\title{
SISTEM INFORMASI REKOMENDASI PEMILIHAN SEKOLAH DASAR DENGAN METODE AHPSTUDI KASUS SURABAYA BARAT
}

\author{
Suryo Atmojo ${ }^{1}$, Suzana Dewi ${ }^{2}$,Nurwahyudi Widhiyanta ${ }^{3}$, Ruli Utami ${ }^{4}$ \\ 1,2,3 Universitas Wijaya Putra \\ Surabaya, Indonesia \\ suryoatmojo@uwp.ac.id, suzanadewi@uwp.ac.id,nurwahyudiwidhiyanta@uwp.ac.id \\ ${ }^{4}$ Institut Teknologi Adhi Tama \\ Surabaya, Indonesia \\ ruli.utami@itats.ac.id
}

\begin{abstract}
Abstrak
Pemilihan sekolah dengan tepat ialah salah satu langkah yang penting. Pilihan untuk sekolah saat ini, akan memengaruhi proses pendidikan serta masa depan. Pada proses pemilihan sekolah jika pilihannya tepat, hasil belajar yang didapat di sekolah akan menjadi modal dalam mengikuti pendidikan pada jenjang yang lebih tinggi, serta akan memengaruhi bidang pekerjaan yang akan ditekuni. Banyaknya pertimbangan yang perlu diperhatikan saat memilih sekolah khususnya sekolah dasar, menjadikan proses pemilihan sekolah pada saat ini menjadi proses yang tidak mudah. Banyaknya pilihan sekolah membuat orang tua dan anak bingung untuk memilih. Solusi pada masalah penentuan sekolah berdasarkan kriteria yang kompleks yaitu menggunakan sistem pendukung keputusan. Sistem pendukung keputusan atau SPK ialah sebuah sistem dengan pendekatan sistematis, dengan proses awal yaitu pengumpulan faktafakta, penetapan kriteria keputusan guna memilih alternatif tindakan yang paling tepat sebagai solusi keputusan. Berdasarkan hal di atas, penulis tertarik melakukan pemilihan sekolah berdasarkan kriteria-kriteria yang diinginkan menggunakan metode AHP (analitycal hierarchy process). Berdasarkan hasil penelitian dapat disimpulkan bahwa sistem ini dapat mempermudah pemilihan sekolah dasar sesuai dengan kriteria yang dipilih oleh wali murid. Dengan menggunakan metode AHP sesuai kriteria yang dipilih oleh user wali murid.
\end{abstract}

Kata Kunci: SPK, AHP, Sekolah, Sistem 


\begin{abstract}
Selection of schools appropriately; one important step. The choice of school today, will influence the educational process as well as the future. In the school selection process, if the choice is right, the learning outcomes obtained at school will become capital in attending higher education levels and will affect the field of work to be pursued. The number of considerations that need to be considered when choosing an elementary school makes the current school selection process difficult process. The number of school choices makes parents and children confused to choose. The solution to the problem of determining the school is based on complex criteria, namely using a support system. A decision support system or DSS is a system with a systematic approach, with an initial process that is based on facts, establishing criteria to select the most appropriate alternative action as a decision solution. Based on the above, the authors are interested in selecting schools based on criteria using the AHP method (hierarchical analysis process). Based on the research results, it can be ignored that this system can facilitate the selection of elementary schools according to the criteria chosen by the guardians of the students. By using the AHP method according to the criteria chosen by the student guardian.
\end{abstract}

Keywords: DSS, AHP, School, System 


\section{PENDAHULUAN}

Salah satu faktor yang berperan dalam membangun negara Indonesia yang maju adalah pendidikan. Pengembangan pendidikan dirasa sangatlah diperlukan, karena pendidikan yang bermutu dapat meningkatkan kecerdasan sebuah negara. Pendidikan juga merupakan sebuah investasi dalam pengembangan sumber daya manusia guna mengarungi kehidupan.

Sekolah ialah lembaga pendidikan formal yang secara sistematis menjalankan program pengajaran, bimbingan, dan latihan guna membantu siswa agar dapat mengembangkan potensinya pada aspek spiritual, moral, emosional, intelektual maupun sosial. Saat ini pemilihan sekolah yang tepat merupakan proses yang sulit bagi para orang tua (Fitriana \& Widayani, 2016). Pemilihan sekolah dengan tepat ialah salah satu langkah yang penting. Pilihan untuk sekolah saat ini, akan memengaruhi proses pendidikan serta masa depan. Pada proses pemilihan sekolah jika pilihannya tepat, maka apa yang didapat di sekolah akan menjadi modal yang cukup dalam mengikuti pendidikan pada jenjang yang lebih tinggi, serta akan mempengaruhi bidang pekerjaan yang akan ditekuni (Habiby \& Yamasari, 2017). Dalam proses menentukan sekolah yang baik dan tepat tidaklah mudah, hal tersebut disebabkan karena banyaknya pertimbangan yang perlu diperhatikan dalam memilih sekolah khususnya pada sekolah dasar, serta banyaknya pilihan sekolah yang membuat orang tua dan anak bingung untuk memilih (Harahap, 2015).
Surabaya memiliki 680 sekolah dasar yang terdiri dari sekolah negeri dan swasta yang diperoleh dari (profilsekolah.dispendik.surabaya.go.id). Menyadari betapa pentingnya dalam menentukan pilihan sekolah yang tepat dari jumlah data yang banyak, maka perlu pengelompokan sekolah terlebih dahulu berdasarkan lokasi terdekat dari tempat tinggal menuju ke sekolah, sehingga bisa mempermudah dalam pemilihan sekolah.

Solusi pada masalah penentuan sekolah berdasarakan kriteria yang kompleks ialah Sistem Pendukung Keputusan (SPK) dimana dapat membantu orang tua dalam menentukan pilihan sekolah dasar terbaik bagi anak mereka. Pada penelitian ini, SPK yang akan dibuat juga akan dikombinasikan dengan Sistem Informasi Geografis (SIG) dimana akan menjadi alat bantu untuk menampilkan data-data sekolah dalam bentuk maps (Ariyanti et al., 2015). Pemanfaatan SIG diharapkan dapat membantu orang tua untuk mengakses informasi data sekolah khususnya lokasi sekolah menjadi lebih mudah (Ramadhani et al., 2016). SPK ialah sistem dengan pendekatan sistematis, yang diawali pengumpulan fakta-fakta, menetapkan sejumlah kriteria keputusan untuk memilih alternatif tindakan yang paling tepat sebagai solusi. Salah satu metode Sistem Pendukung Keputusan (SPK) yang bisa mengatasi masalah tersebut adalah AHP (analitycal hierarchy process). AHP ialah metode hierarki fungsional dengan input utamanya persepsi manusia (Aqli et al., 2016). Metode AHP digunakan karena mampu menghasilkan output yang lebih konsisten (Narti et al., 2019). Metode AHP menghasilkan output 
berdasarkan urutan ranking dari setiap alternatif yang ada (Munthafa \& Mubarok, 2017). K-Means sebagai salah satu metode data clustering yang mengelompokkan data dalam bentuk satu atau lebih cluster. Datadata yang memiliki karakteristik yang sama dikelompokkan dalam satu cluster dan data yang memiliki karakteristik yang berbeda pada cluster yang lain (Imantika et al., 2019). Setelah data yang sudah dikelompokan dengan metode K-means selesai, proses selanjutnya untuk perangkingan pemilihan sekolah dasar menggunakan metode AHP. Begitu banyaknya pendekatan yang digunakan oleh para pengguna metode AHP, khususnya dalam hal seleksi terhadap sesuatu fenomena. Berbagai kalangan akademisi banyak menggunakan Metode AHP, mulai dari kajian teori hingga sampai pada implementasi dalam kehidupan sehari-hari,

\section{METODE PENELITIAN}

Metode penelitian yang digunakan pada tahap pengembangan aplikasi adalah metode waterfall (Christian et al., 2018):

1. Requirement Gathering and analysis

Tahap ini merupakan proses mengumpulkan kebutuhan secara lengkap untuk berikutnya dilakukan proses analisis dan pendefinisian kebutuhan yang harus dipenuhi oleh program yang akan dibangun. tahapan ini harus dikerjakan secara lengkap untuk bisa menghasilkan desain baik.

2. Design

Dalam tahap ini pengembang akan menghasilkan sebuah sistem secara keseluruhan dan menentukan alur perangkat lunak hingga algoritma yang detail.

\section{Implementation}

Tahapan dimana seluruh desain diubah menjadi kode progam. Kode progam yang dibuat berupa modul yang akan diintregasikan menjadi sistem yang lengkap.

4. Integration \& Testing

Di tahap ini dilakukan penggabungan modul-modul yang sudah dibuat dan dilakukan pengujian ini dilakukan untuk mengetahui apakah software yang dibuat telah sesuai dengan desainnya dan fungsi pada software terdapat kesalahan atau tidak.

5. Verification adalah klien atau pengguna menguji apakah sistem tersebut telah sesuai dengan yang disetujui.

6. Operation \& Maintenance yaitu instalasi dan proses perbaikan sistem sesuai yang disetujui.

\section{HASIL PENELITIAN DAN PEMBAHASAN}

1. Data Flow Diagram

Berikut ialah data flow diagram dari sistem penunjang keputusan pemilihan sekolah dasar studi kasus area Surabaya barat yang dibuat.

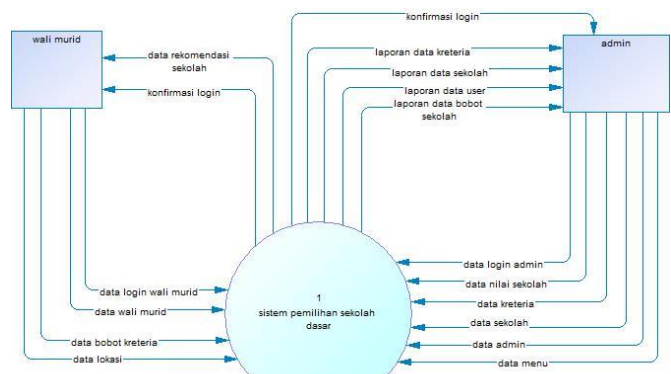

Gambar 1. Data Flow Diagram

\section{Conceptual Data Model}

Berikut adalah conceptual data model dari sistem pemilihan sekolah dasar yang dibuat 


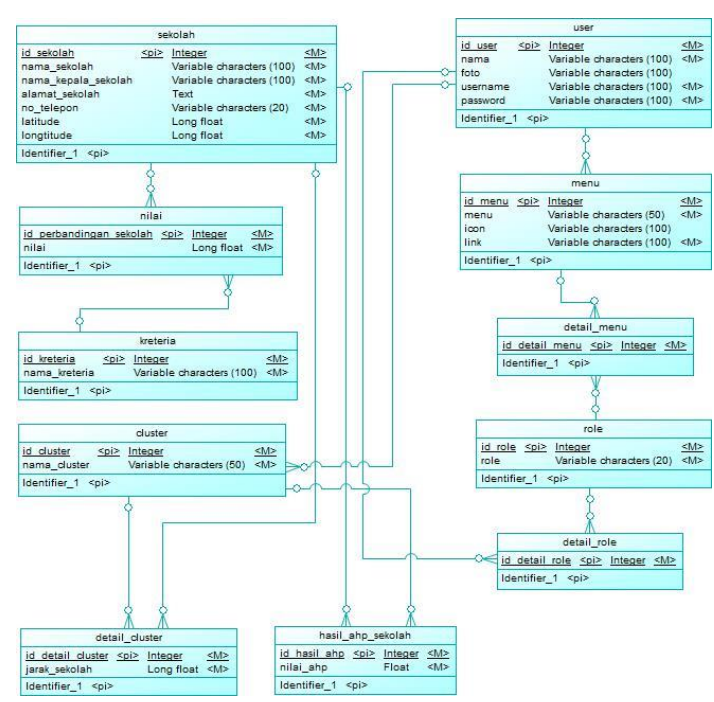

Gambar 2. Conceptual Data Model

\section{Physical Data Model}

Berikut adalah physical data model dari aplikasi yang dibuat

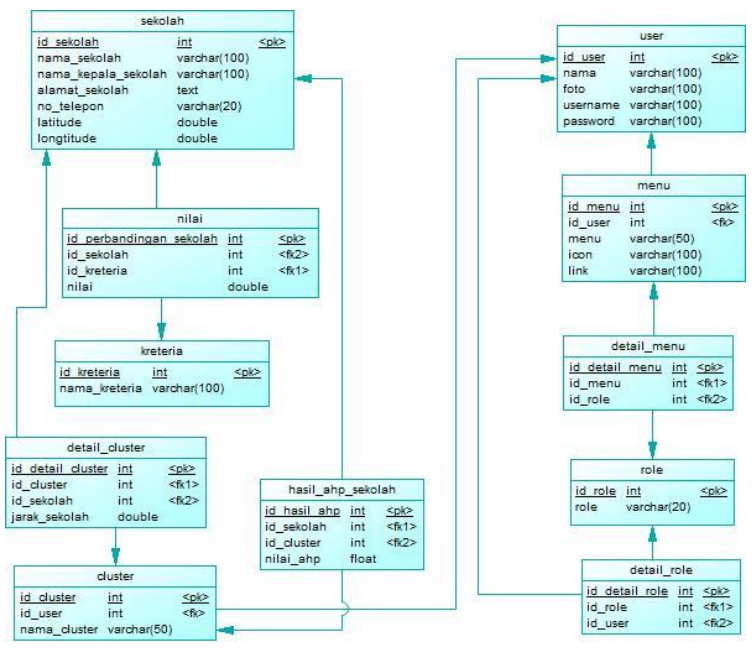

Gambar 3. Conceptual Data Model

4. Perhitungan AHP

Tabel 1. Perhitungan AHP

$$
\text { perpus biaya akreditasi lab }
$$

\begin{tabular}{lrrrr}
\hline perpus & 1 & 0,111111 & 2 & 5 \\
\hline biaya & 9 & 1 & 9 & 9 \\
\hline akreditasi & 0,5 & 0,111111 & 1 & 3 \\
\hline lab & 0,2 & 0,111111 & 0,333333 & 1 \\
\hline jumlah & 10,7 & 1,333333 & 12,333333 & 18 \\
\hline
\end{tabular}

Table 1 adalah hasil bobot kriteria yang dipilih oleh user.
Tabel 2. Normalisasi tabel bobot

\begin{tabular}{|c|c|c|c|c|c|}
\hline & perpus & biaya & $\begin{array}{l}\text { akredi } \\
\text { tasi }\end{array}$ & lab & $\begin{array}{l}\text { rata- } \\
\text { rata }\end{array}$ \\
\hline perpus & 0,093 & 0,083 & 0,16 & 0,27 & 0,154 \\
\hline biaya & 0,84 & 0,75 & 0,72 & 0,5 & 0,70 \\
\hline akreditasi & 0,046 & 0,083 & 0,081 & 0,16 & 0,094 \\
\hline lab & 0,018 & 0,083 & 0,027 & 0,055 & 0,046 \\
\hline jumlah & 1 & 1 & 1 & 1 & 1 \\
\hline
\end{tabular}

normalisasi dari tabel bobot.

Tabel 3. Cluster data normalisasi id jarak perpus-2 biaya-3 akreditasi-4 lab-5

\begin{tabular}{lccccc}
\hline $\mathbf{1}$ & 10,02 & 1 & 200000 & 2 & 0 \\
\hline $\mathbf{6}$ & 8,76 & 2 & 240000 & 2 & 1 \\
\hline $\mathbf{7}$ & 4,98 & 0 & 200000 & 2 & 0 \\
\hline $\mathbf{8}$ & 2,25 & 2 & 200000 & 2 & 1 \\
\hline & 26,01 & 5 & 840000 & 8 & 2 \\
\hline
\end{tabular}

Table 3 merupakan data salah satu hasil cluster yang akan dinormalisasi.

Tabel 4. Cluster data normalisasi

\begin{tabular}{rrrrr}
\hline $\mathbf{1}$ & $\mathbf{0 , 2}$ & $\mathbf{0 , 2 3 8 0 9 5 2 3 8}$ & $\mathbf{0 , 2 5}$ & $\mathbf{0}$ \\
\hline $\mathbf{6}$ & 0,4 & 0,285714286 & 0,25 & 0,5 \\
\hline $\mathbf{7}$ & 0 & 0,238095238 & 0,25 & 0 \\
\hline $\mathbf{8}$ & 0,4 & 0,238095238 & 0,25 & 0,5 \\
\hline & 1 & 1 & 1 & 1 \\
\hline & Table & 4 & merupakan & hasil
\end{tabular}
normalisasi alternatif data sekolah.

Tabel 5. Nilai alternatif-kriteria

\begin{tabular}{rrrrr}
\hline $\mathbf{1}$ & $\mathbf{0 , 0 3 0}$ & $\mathbf{0 , 1 6 7}$ & $\mathbf{0 , 0 2 3}$ & $\mathbf{0}$ \\
\hline $\mathbf{6}$ & 0,061 & 0,201 & 0,023 & 0,023 \\
\hline $\mathbf{7}$ & 0 & 0,167 & 0,023 & 0 \\
\hline $\mathbf{8}$ & 0,061 & 0,167 & 0,023 & 0,023
\end{tabular}

Table 5 merupakan nilai alternatifkriteria.

Tabel 6. Nilai alternatif-kriteria

\begin{tabular}{rr}
\hline $\mathbf{1}$ & $\mathbf{0 , 2 2 2 3 5 7 5}$ \\
\hline $\mathbf{6}$ & 0,309851561 \\
\hline $\mathbf{7}$ & 0,191520939 \\
\hline $\mathbf{8}$ & 0,276269999
\end{tabular}


5. Halaman Login

Pada saat pertama kali dibuka, laman perangkat sistem akan menampilkan tampilan menu login, Gambar 4 adalah antarmuka menu login.

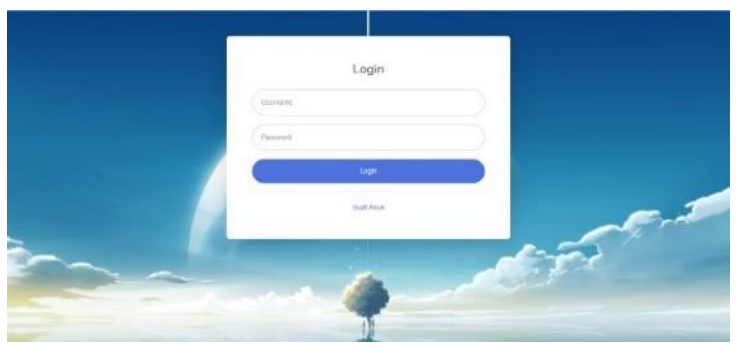

Gambar 4. Halaman Login

6. Desain Aplikasi (Halaman Admin)

Gambar 5 adalah tampilan dashboard admin Ketika admin berhasil login pada Sistem Pendukung Keputusan.

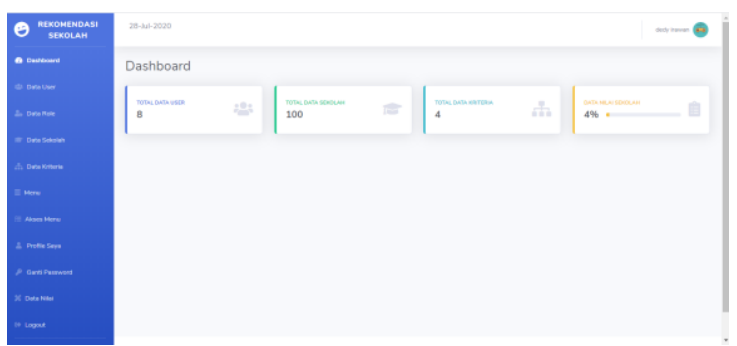

Gambar 5. Halaman Admin

7. Desain Aplikasi (Halaman Wali Murid)

Gambar 6 adalah tampilan halaman wali murid ketika wali murid menggunakan perhitungan Sistem Pendukung Keputusan.

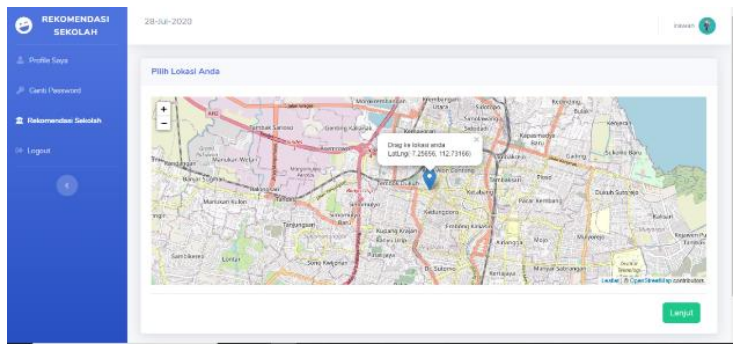

Gambar 6. Halaman Wali Murid

8. Tampilan Hasil AHP

Gambar 7 adalah tampilan hasil perhitungan AHP pada Sistem Pendukung Keputusan.

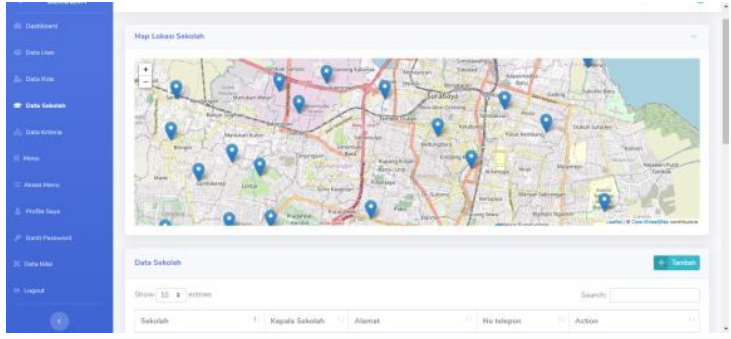

Gambar 7. Halaman Hasil AHP

Gambar 7 merupakan tampilan hasil dari AHP yang akan menampilkan beberapa rekomendasi sekolah sesuai dengan kriteria yang dipilih oleh wali murid. Berikut kode programnya:

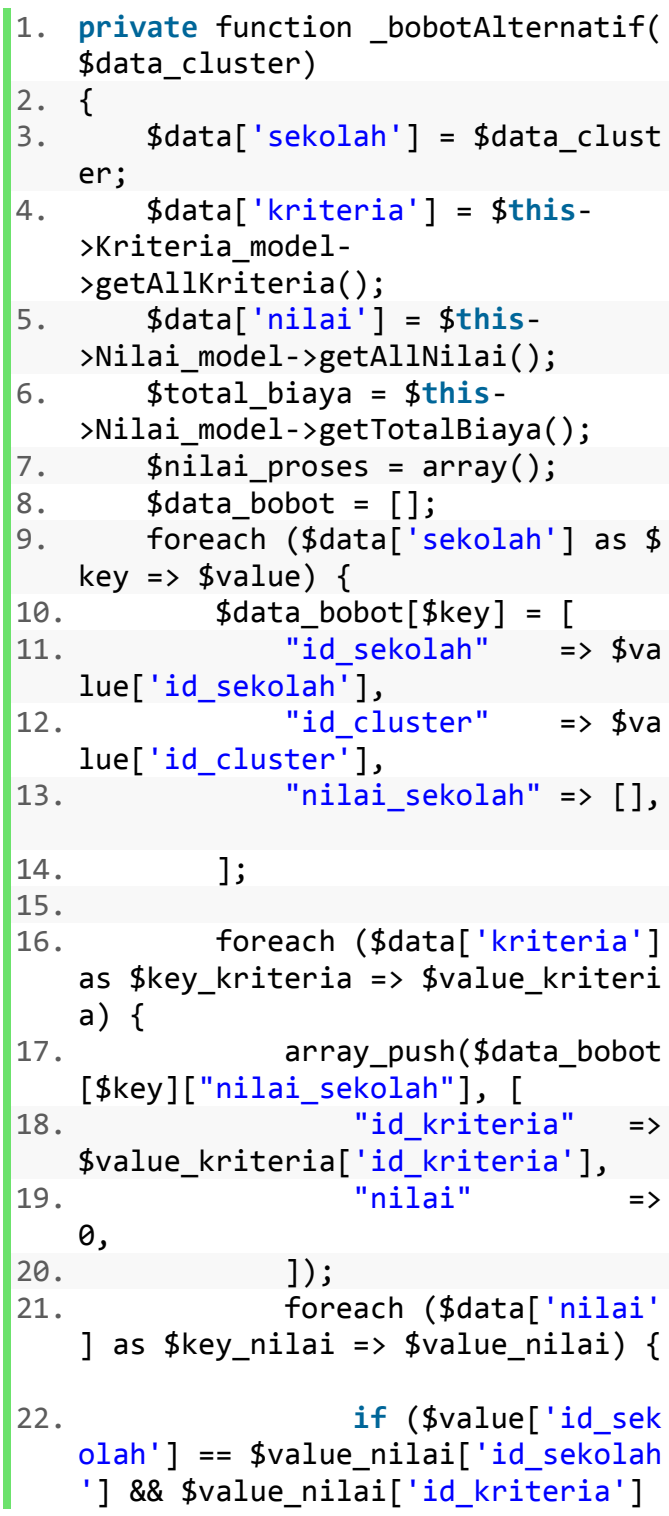


$=$ \$value_kriteria['id_kriteria'])

23. \{

\$data_bobot [\$k ey]['nilai_sekolah'][\$key_kriteria ]['nilai'] = \$value_nilai['nilai']

24.

25.

26.

27.

28.

30.

31. private function _jumlahBobotAlter natif( $\$$ data_bobot)

32. \{

33. \$data['kriteria'] = \$this>Kriteria_model-

>getAllKriteria();

34. \$jumlah_bobot $=[]$;

35. foreach (\$data['kriteria'] as \$key_kriteria $=>$ \$value_kriteria) \{

36.

$\$$ hasil $=0$;

37. foreach (\$data_bobot as $\$ \mathrm{k}$ ey_bobot $\Rightarrow$ \$value_bobot) \{

38. \$hasil $+=$ (double) $\$ v a l$ ue_bobot['nilai_sekolah'][\$key_kri teria]['nilai'];

39. \}

40. array_push(\$jumlah_bobot,

41. "id_kriteria" $\quad$ "> \$va lue_kriteria['id_kriteria'],

42. "jumlah_bobot" => \$ha sil, ]);

44. $\}$

45. return \$jumlah_bobot;

46. $\}$

47.

48. private function normalisasiAlter natif(\$data_bobot, \$jumlah_bobot)

49. \{

50. \$data_normalisasi $=[]$;

51. foreach (\$data_bobot as \$key_b obot $=>$ \$value_bobōt) \{

52. \$data_normalisasi[\$key_bob ot $]=[$

53. "id_sekolah" $\quad \Rightarrow \$ v a$ lue_bobot['id_sekolah'], $\quad \Rightarrow \$ v a$ lue_bobot['id_cluster'], "nilai_sekolah" $\Rightarrow[]$,

];

57. foreach (\$value_bobot[' nil $\Rightarrow$ \$value_nilai_sekolah) \{

58. foreach (\$jumlah_bobot as $\$$ key_jml_bobot $=>$ \$value_jml_bo bot) \{
59.

60.

ot ['id_kriteria'] == \$value_nilai sekolah['id_kriteria']) \{

61. array push $(\$ d a$ ta_normalisasi[\$key_bobot]["nilai_ sekolah"], [

62. "id_kriter ia" $\quad \Rightarrow$ \$value_nilai_sekolah[ 'id_kriteria'],

63. malisasi" $\Rightarrow$ (double)\$value jm bot ['jumlah_bobot'] != 0 ? (double )\$value_nilai_sekolah['nilai']/(do uble)\$vālue_jml_bobot['jumlah_bobo $\left.t^{\prime}\right]: 0$

64.

65.

66.

67.

68.

69

70. $\}$

71.

72. private function_jumlahNormalisas iAlternatif(\$data_normalisasi)

73. \{

74

\$data['kriteria'] = \$this -

>Kriteria_model-

>getAllKriteria();

75. \$jumlah_normalisasi $=[]$;

76. foreach (\$data['kriteria'] as \$key_kriteria $=>$ \$value_kriteria) \{

77. $\quad$ \$hasil $=0$;

78. foreach (\$data_normalisasi as \$key_normalisasi $\Rightarrow$ \$value_norm alisasi) \{

79.

\$hasil $+=$ (double)\$val ue normalisasi['nilai_sekolah'][\$k ey_kriteria]['nilai_normalisasi'];

80. $\}$ 81. array_push(\$jumlah_normali sasi, [

82. "id_kriteria" $\Rightarrow$ \$value_kriteria['id_kriteria'],

83. "jumlah_normalisasi" $\Rightarrow \$$ hasil,

84. ]);

85. \}

86. // echo '<pre>';

87. // var_dump(\$jumlah_normalisas i);

88. I/ echo '</pre>';

89. return \$jumlah_normalisasi;

90. $\}$

91.

92. private function eigenAlternatifK riteria(\$normalisasi_alternatif, \$ data_rata_eigen)

93. \{ 


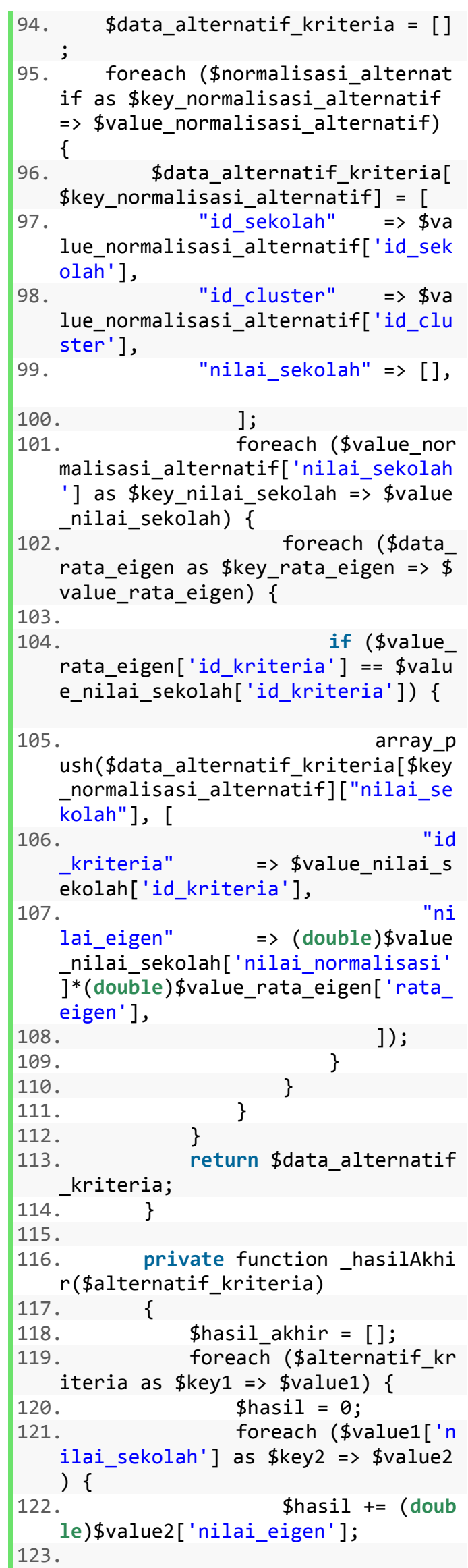

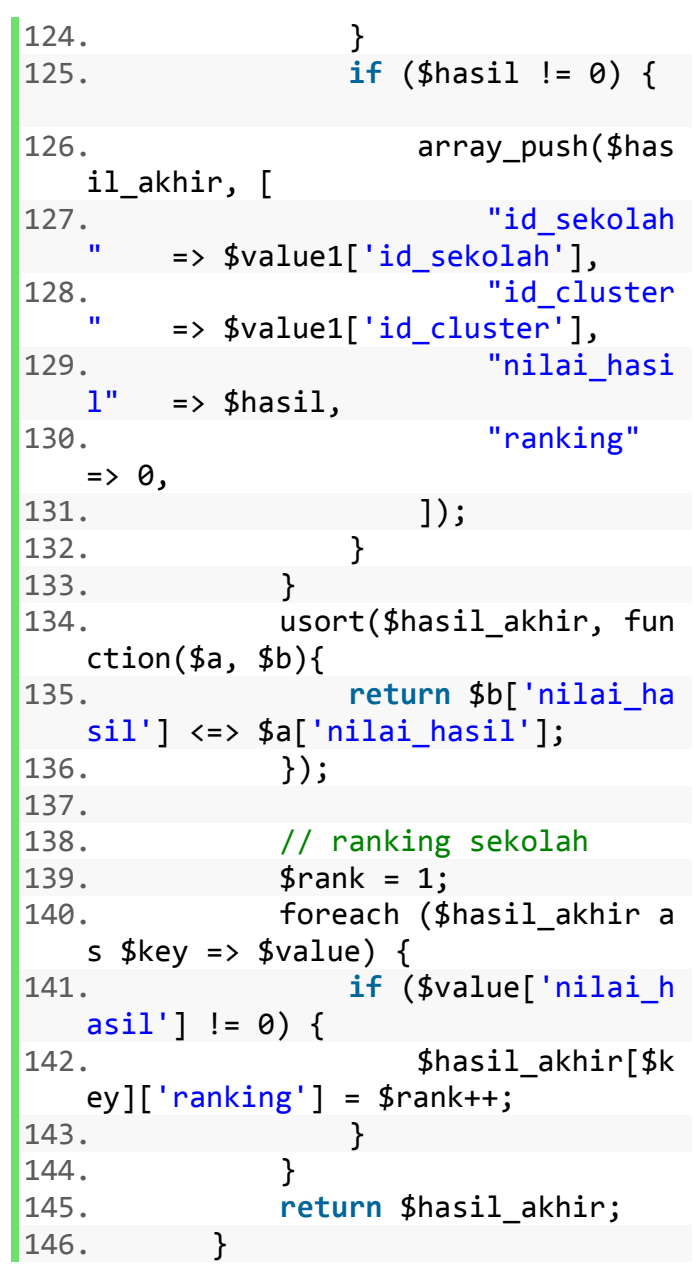

\section{KESIMPULAN DAN SARAN}

Berdasarkan hasil penelitian dapat disimpulkan bahwa sistem ini dapat mempermudah pemilihan sekolah dasar sesuai dengan kriteria yang dipilih oleh wali murid. Dengan menggunakan metode AHP sesuai kriteria yang dipilih oleh user wali murid.

Penambahan fitur yang diharapkan pada pengembangan selanjutnya bisa berupa :

- Data sekolah masih belum berdasarkan data asli atau masih data contoh.

- Aplikasi ini masih menggunakan web, bisa dikembangkan menjadi aplikasi android yang bisa mempermudah pengguna smartphone. 


\section{DAFTAR PUSTAKA}

Aqli, I., Ratnawati, D. E., \& Data, M. (2016). Sistem Rekomendasi Pemilihan Sekolah Menengah Atas Sederajat Kota Malang Menggunakan Metode AHP ELECTRE Dan TOPSIS. Jurnal Teknologi Informasi Dan Ilmu Komputer, 3(4). https://doi.org/10.25126/jtiik.2 01634228

Ariyanti, R., Khairil, \& Kanedi, I. (2015). Pemanfaatan Google Maps Api Pada Sistem Informasi Geografis Direktori Perguruan Tinggi Di Kota Bengkulu. Jurnal Media Infotama, 11(2).

Christian, A., Hesinto, S., \& Agustina, A. (2018). Rancang Bangun Website Sekolah Dengan Menggunakan Framework Bootstrap ( Studi Kasus SMP Negeri 6 Prabumulih ). Jurnal Sisfokom (Sistem Informasi Dan Komputer), 7(1). https://doi.org/10.32736/sisfok om.v7i1.278

Fitriana, A., \& Widayani, T. (2016). Sistem Pendukung Keputusan Pemilihan Sekolah Dasar Islam di Pontianak. Creative Information Technology Journal, $4(1)$. https://doi.org/10.24076/citec.2 016v4i1.94

Habiby, A., \& Yamasari, Y. (2017). Sistem Informasi Sekolah Berbasis Web (Studi Kasus : TK Kusuma Putra Mojokerto). Jurnal Manajemen Informatika, 7(2).

Harahap, A. A. (2015). SISTEM PENDUKUNG KEPUTUSAN PENENTUAN JURUSAN DENGAN METODE ANALYTICAL HIERARCHY
PROCESS ( STUDI KASUS : SMK SWASTA KARTINI UTAMA SEI RAMPAH ). Pelita Informatika Budi Darma, IX, Nomor.

Imantika, D., Bachtiar, F. A., Rokhmawati, R. I., Studi, P., Informasi, S., Komputer, F. I., Brawijaya, U., \& Process, A. H. (2019). Penerapan metode k-means clustering dan analytical hierarchy process (ahp) untuk pengelompokan kinerja guru dan karyawan pada sma brawijaya smart school. Jurnal Pengembangan Teknologi Informasi Dan Ilmu Komputer J-PTIIK, 3(8).

Munthafa, A., \& Mubarok, H. (2017). Penerapan Metode Analytical Hierarchy Process Dalam Sistem Pendukung Keputusan Penentuan Mahasiswa Berprestasi. Jurnal Siliwangi, 3(2).

Narti, N.-, Sriyadi, S., Rahmayani, N., \& Syarif, M. (2019). Pengambilan Keputusan Memilih Sekolah Dengan Metode AHP. Jurnal Informatika, 6(1). https://doi.org/10.31311/ji.v6i1 .5552

Ramadhani, H., Awaluddin, M., \& Nugraha, A. (2016). APLIKASI WEBGIS UNTUK INFORMASI PERSEBARAN SEKOLAH MENENGAH ATAS DAN MADRASAH ALIYAH DI KABUPATEN KUDUS MENGGUNAKAN HERE MAP API. Jurnal Geodesi Undip, 5(1). 